\title{
Clinical Communications
}

\section{Drug-induced anaphylaxis, elicitors, risk factors, and management in Latin America}

Edgardo José Jares, $M D^{a}$, Ricardo Cardona Villa, $M D^{b}$, Mario Sánchez-Borges, $\mathrm{MD}^{c}$, Alicia de Falco, $\mathrm{PhD}^{d}$, Luis Felipe Ensina, $\mathrm{PhD}^{\circ}$, Jonathan A. Bernstein, $\mathrm{MD}^{\dagger}$, Alfredo Arias-Cruz, MD ${ }^{9}$, Ivan Cherrez-Ojeda, MD, MSc ${ }^{h}$, Blanca Morfín Maciel, MD',

Alejandra Macías-Weinmann, MD',

Sandra González Díaz, MD', Dirceu Sole, PhD ${ }^{k}$, Pedro Giavina Bianchi, $M D^{\prime}$, Susana de Barayazarra, $\mathbf{M D}^{m}$, Mabel Cuello, $\mathrm{MD}^{n}$, Miguel Vinuesa, $\mathrm{MD}^{\circ}$, Juan Carlos Calderón, $\mathrm{MD}^{\mathrm{p}}$, Viviana A. Zanacchi, $\mathrm{MD}^{\mathrm{m}}$, Silvana Monsell, MD ${ }^{a}$, Mara Morelo Rocha Felix, $\mathrm{PhD}^{a}$, Carlos Serrano Reyes, MD', Pedro Piraino, MDs, Rodolfo Jaller, MD ${ }^{t}$, Patricia Guerzet Ayres Bastos, $\mathrm{MD}^{\mathrm{e}}$, and Maximiliano Gómez, MD, $\mathrm{PhD}^{\mathrm{u}}$; On behalf of "Latin America Drug Allergy Interest Group"

\section{Clinical Implications}

- Nonsteroidal anti-inflammatory drugs were the most frequent triggers of drug-induced anaphylaxis in Latin America, whereas antibiotics elicited faster onset and more severe reactions. An improvement was observed in epinephrine use and adherence to guidelines in the emergency department treatment of anaphylaxis in Latin America compared with our last report.

\section{TO THE EDITOR:}

Drugs are among the most frequent elicitors of anaphylaxis, especially in adults and hospitalized patients. ${ }^{1}$ Although studies from France and Portugal found that beta-lactam antibiotics were the most frequent drug-induced anaphylaxis (DIA) elicitors, ${ }^{2,3}$ the main drugs claimed as triggers of DIA in Latin America (LA) are nonsteroidal anti-inflammatory drugs (NSAIDs), ${ }^{4}$ The aim of this study was, using a drug anaphylaxis-specific questionnaire, to provide new data on the clinical presentation, risk factors, and acute treatment of DIA in LA.

An online survey modified from the European Network of Drug Allergy questionnaire was used to obtain patient demographic data and the clinical features, severity, and chronology of anaphylactic reactions ${ }^{5}$ (severity grading system and causality definitions in Tables E1 and E2 in this article's Online Repository at www.jaci-inpractice.org) to implicated drugs over 2 years. In addition, acute management of the DIAs administered to patients was obtained. The results included all the patients with DIA reported to the registry between January 2017 and November 2018 by 22 allergy units from 8 LA countries. A total of 286 DIA cases were reported. The main demographic data are summarized in Table I.
Mild, moderate, severe, and fatal reactions were present in $4.20 \%, 59.44 \%, 36.01 \%$, and $0.35 \%$ of patients, respectively. Children/adolescents, adults (18-59 years old), and elderly patients (>60 years old) experienced severe reactions in $12 \%$, $37.17 \%$, and $57.78 \%$ of cases, respectively (children/adolescents vs adults: $P<.001$; adults vs elderly: $P<.05)$. In the unadjusted logistic regression, a 10 -fold increase (odds ratio, $10.03 ; 95 \% \mathrm{CI}$, 3.55-28.33) and a 4 -fold increase (odds ratio, 4.44; $95 \% \mathrm{CI}$, $1.80-10.93)$ in the chance for a severe reaction was found in elderly and adults, respectively, compared with childrenadolescents. Older age has been recognized previously as a risk factor for more severe anaphylaxis. ${ }^{4,6}$

No significant difference in severity was found between patients with or without an allergic history (severe reactions $31.4 \%$ vs $40.3 \%, P=.093$ ), or an asthma history (severe reactions: $30.8 \%$ vs $37.6 \% ; P=.354$ ).

Previous reaction with the implicated drug, or a drug from the same group, was present in $24.5 \%$ of patients (milder reactions, $18.6 \%$; similar or more severe reaction $5.9 \%$ ). These DIA reactions emphasize the importance of educating physicians about taking a careful history regarding previous drug-induced hypersensitivity reactions.

Oral (68.2\%) and intravenous (IV) (22\%) were the most common routes associated with DIAs. The IV route induced severe reactions in $48.3 \%$ of patients compared with $31.3 \%$ for the oral route $(P<.05)$. In addition, drugs administered via the IV route induced quicker onset of reactions; $55.2 \%$ versus $20.6 \%$ during the first 10 minutes for the IV and oral routes, respectively $(P<.00001)$. This is in accordance with other studies where patients receiving parenterally administered drugs presented more severe and faster reactions. $2,4,7$

The main inducers causing certain/probable DIA were NSAIDs $(54.6 \%)$, beta-lactam antibiotics $(16.6 \%)$, and non-beta-lactam antibiotics $(6.4 \%)$. The predominant reactions to NSAIDS might be related to the fact that these drugs are easily obtained over the counter in most LA countries and selfmedication especially with NSAIDs is very common in this region. Ibuprofen $(24.3 \%)$ and metamizole $(21.7 \%)$ were the most frequently implicated NSAIDs in the entire population, whereas diclofenac was the most prevalent NSAID in the elderly group $(40.74 \%)$, possibly linked to their higher use for osteoarthritis. Antibiotics more frequently induced severe reactions (beta-lactams $43.4 \%$ and non-beta-lactams $44.4 \%$ ) compared with NSAIDs $(27.7 \%)(P<.05)$. Beta-lactam antibiotic reactions occurred during the 10 -minute period after drug intake in $42.3 \%$ of cases compared with NSAID reactions, which occurred in $19.9 \%$ of cases during the same time period $(P<.005)$. These findings might be explained by differences in the involved mechanisms. Beta-lactam-induced DIA are believed to be IgE-mediated reactions that can result in systemic reactions including vascular instability, whereas NSAID DIA are believed to be primarily related to imbalance of prostaglandins/ leukotrienes production due to cyclooxygenase blocking that typically manifest as cutaneous and respiratory reactions. ${ }^{8}$

Most patients received glucocorticoids $(80.1 \%)$ and antihistamines $(80.4 \%)$. Epinephrine was administrated in $49.6 \%$ of cases, intramuscularly $41.6 \%$ and subcutaneously $8 \%$ of cases 
TABLE I. Demographic data of all questionnaire respondents

\begin{tabular}{|c|c|c|c|c|}
\hline & Overall & Children-adolescents $(0.17 \mathrm{y})$ & Adults $(18-83 \mathrm{y})$ & \\
\hline Characteristic & $(N=286)$ & $(n=50)$ & $(n=236)$ & $P$ value adults/children-adolescents \\
\hline $\bar{N}$ & 286 & 50 & 236 & \\
\hline Age $(y)$, median & $37(24-52)$ & $11.0(8-14)$ & $41.0(31-56)$ & $<.001^{+}$ \\
\hline \multicolumn{5}{|l|}{$\operatorname{Sex}, \%$} \\
\hline Male & 35.7 & 58.0 & 30.9 & $<.000^{*}$ \\
\hline Female & 64.3 & 42.0 & 69.1 & \\
\hline Allergic background, $\%$ & 47.9 & 66.0 & 44.1 & $<.005^{*}$ \\
\hline Rhinitis, \% & 36.7 & 52.0 & 33.5 & $<.014^{*}$ \\
\hline Asthma, \% & 18.2 & 36 & 14.4 & $<.000^{*}$ \\
\hline Food allergy, \% & 6.3 & 8.0 & 5.9 & NS \\
\hline Atopic dermatitis, $\%$ & 4.9 & 12.0 & 3.4 & $<.010^{*}$ \\
\hline Hymenoptera venom allergy, \% & 3.8 & 14.0 & 1.7 & $<.000^{*}$ \\
\hline Latex allergy \% & 1.7 & 2.0 & 1.7 & NS \\
\hline Previous drug reactions, \% & 32.5 & 26.0 & 33.9 & NS \\
\hline Family history of allergy, $\%$ & 28.7 & 48.0 & 24.6 & $<.007 *$ \\
\hline
\end{tabular}

NS, Nonsignificant.

$* P<.05, \chi^{2}$.

$\dagger P<.05$, Mann-Whitney $U$ test.

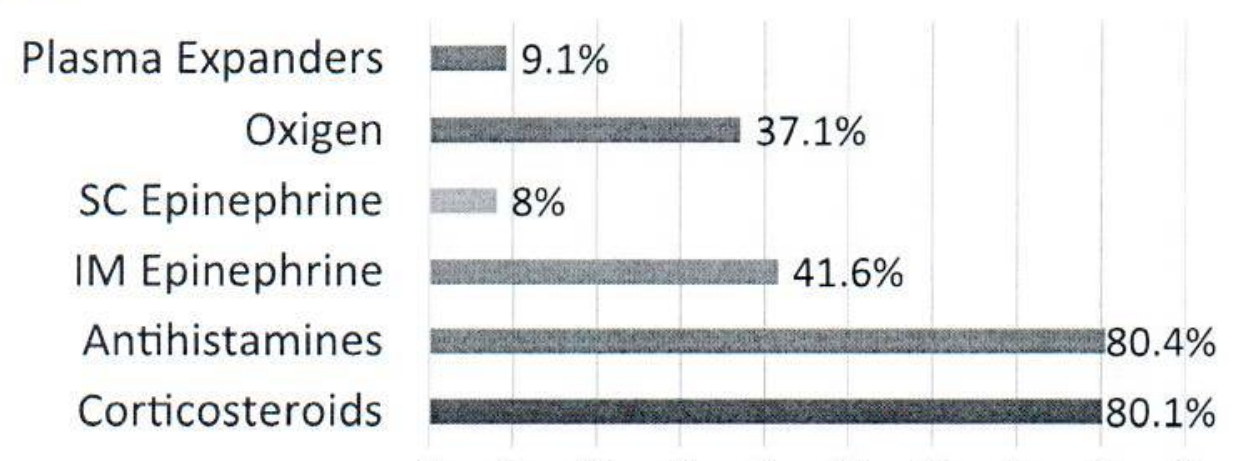

A
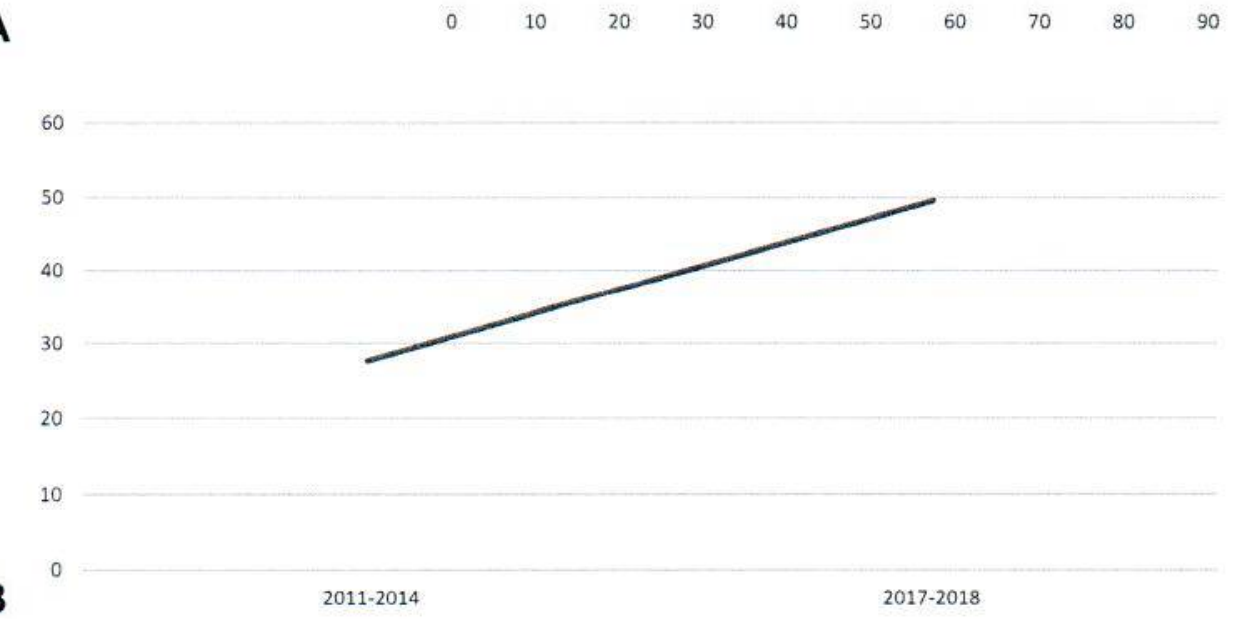

FIGURE 1. (A) Acute treatment of anaphylaxis. (B) Change in epinephrine use in Latin America from 2011-2014 (Jares et al ${ }^{4}$ ) to 2017-2018. SC, Subcutaneous; IM, intramuscular. 
(Figure 1, A). Intramuscular epinephrine is the cornerstone of anaphylaxis treatment, ${ }^{9}$ but its use has remained low in different parts of the world. In a previous study on DIA in LA, we found that epinephrine was used only in $27.6 \%$ of cases. ${ }^{4}$ (Figure 1, B). We speculate that the use of epinephrine in these situations is improving with continued education and awareness. Glucocorticoids are used in most of the patients with DIA, in spite of the lack of evidence supporting its effectiveness.

Biphasic anaphylaxis was present in 11 patients $(3.84 \%)$. Severe reactions were present in $45.45 \%$ of patients with biphasic and $36 \%$ with nonbiphasic anaphylaxis $(P=.53$, nonsignificant). The biphasic group received epinephrine in $27.27 \%$ of cases and systemic glucocorticoids in $90.90 \%$ of cases during the early phase response. This is in contrast to the nonbiphasic group that received epinephrine in $50.91 \%(P=.14$, nonsignificant $)$ of cases and systemic glucocorticoids in $80 \%$ ( $P=.41$, nonsignificant) of cases. Although not significant, this trend for reduced biphasic reactions in those patients treated with epinephrine early on is consistent with reports suggesting that epinephrine is more effective than systemic glucocorticoids at preventing biphasic reactions. ${ }^{10}$

This study has a number of strengths because it is a large DIA population from LA using a validated questionnaire survey. Furthermore, clinical evaluations were performed in Allergy Units, permitting a more accurate trigger diagnosis.

However, limitations include lack of generalizability because patients were from Allergy Units, and their management may not reflect care provided in General Medicine Units. Furthermore, this was a retrospective descriptive questionnaire study that has inherent reporting bias.

In summary, this study found that NSAIDs were the most frequent triggers of DIA in LA, whereas antibiotics elicited faster onset and more severe reactions. Epinephrine was used in almost half the patients with DIA, mostly by the intramuscular route, demonstrating improved adherence to guidelines in the ED treatment of anaphylaxis since our last survey.

"LIBRA Foundation, Buenos Aires, Argentina

'Universidad de Antioquia, Medellín, Colombia

${ }^{\text {CC}}$ Centro Medico-Docente La Trinidad, Caracas, Venezuela

'Universidad Nacional de La Plata, La Plata, Argentina

'Federal University of São Paulo, São Paulo, Brazil

'University of Cincinnati, Cincinnati, Ohio

${ }^{B}$ Universidad Autónoma de Nuevo León, Monterrey, México

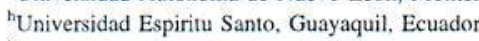

${ }^{i}$ Hospital San Angel, Mexico, Mexico

Juniversidad Autónoma de Nuevo León, Monterrey, México

${ }^{k}$ Federal University of São Paulo, Escola Paulista de Medicina, São Paulo, Brazil

'University of São Paulo, São Paulo, Brazil
${ }^{m}$ Nuevo Hospital San Roque, Córdoba, Argentina

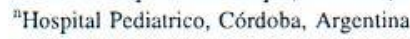

'Universidad de Rosario, Rosario, Argentina

${ }^{\mathrm{P}}$ Respiralab, Guayaquil, Ecuador

${ }^{\mathrm{q}}$ Federal Hospital of Servidores do Estado, Rio De Janeiro, Brazil

'Fundación Valle del Lili, Cali, Colombia

sInstituto de Previsión Social-Hospital Central, Asunción, Paraguay

'Centro de Asma, Alergia c Inmunología Rodolfo Jaller, Barranquilla, Colombia

"Fundación Ayre, Salta, Argentina

Conflicts of interest: The authors declare that they have no relevant conflicts of interest.

Received for publication May 5, 2019; revised October 6, 2019; accepted for publication October 7, 2019.

Available online $\mathbf{m}$

Corresponding author: Edgardo José Jares, MD, Av Rivadavia 14276, Ramos Mejía, Provincia de Buenos Aires, Argentina. E-mail: edgardo.jares@gmail.com. 2213-2198

(c) 2019 American Academy of Allergy, Asthma \& Immunology

hups://doi.org/10.1016/j.jaip. 2019.10.002

\section{REFERENCES}

1. Gonzalez-Estrada A, Silvers SK, Klein A, Zell K. Wang XF, Lang DM, Epidemiology of anaphylaxis at a tertiary care center: a report of 730 cases. Ann Allergy Asthma Immunol 2017;118:80-5.

2. Renaudin JM, Beaudouin E, Ponvert C, Demoly P, Moneret-Vautrin DA. Severe drug-induced anaphylaxistanalysis of 333 cases recorded by the Allergy Vigilance Network from 2002 to 2010. Allergy 2013;68:929-37.

3. Ribeiro-Vaz I, Marques J, Demoly P. Polonia J, Gomes ER. Drug-induced anaphylaxis: a decade review of reporting to the Portuguese Pharmacovigilance Authority. Eur J Clin Pharmacol 2013;69:673-81.

4. Jares EJ, Baena-Cagnani CE, Sánchez-Borges M, Ensina LF, Arias-Cruz A, Gómez M, et al. Drug-induced anaphylaxis in Latin American countries. J Allergy Clin Immunol Pract 2015:3:780-8.

5. Sampson HA, Munoz-Furlong A, Campbell RL, Adkinson NF Jr, Bock SA, Branum A, et al. Second symposium on the definition and management of anaphylaxis: summary report: second National Institute of Allergy and Infectious Disease/Food Allergy and Anaphylaxis Network symposium. J Allergy Clin Immunol 2006;117:391-7

6. Sundquist B, Jose J, Pauze D, Pauze D, Wang H, Järvinen KM. Anaphylaxis risk factors for hospitalization and intensive care: a comparison between adults and children in an upstate New York emergency department. Allergy Asthma Proc 2019:40:41-7.

7. Gabrielli S, Clarke AE, Eisman H, Morris J, Joseph L, La Vieille S, et al. Disparities in rate, triggers, and management in pediatric and adult cases of suspected drug-induced anaphylaxis in Canada. Immun Inflamm Dis 2018;6: $3-12$.

8. Dona I, Barrionuevo E, Salas L, Laguna JJ, Agúndez J, Garcia-Martín E, et al. NSAIDs-hypersensitivity often induces a blended reaction pattern involving multiple organs. Sci Rep 2018:8:16710.

9. Muraro A, Roberts G, Worm M, Bilò MB, Brockow K, Fernández Rivas M, et al. Anaphylaxis: guidelines from the European Academy of Allergy and Clinical Immunology. Allergy 2014;69:1026-45.

10. Lee S, Peterson A, Lohse CM, Hess EP, Campbell RL. Further evaluation of factors that may predict biphasic reactions in emergency department anaphylaxis patients. J Allergy Clin Immunol Pract 2017;5:1295-301. 


\section{ONLINE REPOSITORY}

\section{TABLE E1. Severity criteria ${ }^{E}$}

SEVERE (hypoxia, hypotension, or neurologic compromise) Cyanosis or $\mathrm{SpO}_{2}<92 \%$ at any stage, hypotension (systolic blood pressure $<90$ $\mathrm{mm} \mathrm{Hg}$ in adults), confusion, collapse, loss of consciousness, or incontinence

MODERATE (features suggesting respiratory, cardiovascular, or gastrointestinal involvement) Dyspnea, stridor, wheeze, nausea, vomiting, dizziness (presyncope), diaphoresis, chest or throat tightness, or abdominal pain

MILD (skin and subcutaneous tissues only) including generalized erythema, urticaria, periorbital edema, or angioedema

TABLE E2. Causality criteria $^{\mathrm{E} 2}$

CERTAIN

- Event or laboratory test abnormality, with plausible time relationship to drug intake

- Cannot be explained by disease or other drugs

- Response to withdrawal plausible (pharmacologically, pathologically)

- Event definitive pharmacologically or phenomenologically (ie, an objective and specific medical disorder or a recognized pharmacological phenomenon)

- Rechallenge satisfactory, if necessary

PROBABLE/LIKELY

- Event or laboratory test abnormality, with reasonable time relationship to drug intake

- Unlikely to be attributed to disease or other drugs

- Response to withdrawal clinically reasonable

- Rechallenge not required

POSSIBLE

- Event or laboratory test abnormality, with reasonable time relationship to drug intake

- Could also be explained by disease or other drugs

- Information on drug withdrawal may be lacking or unclear

UNLIKELY

- Event or laboratory test abnormality, with a time to drug intake that makes a relationship improbable (but not impossible)

- Disease or other drugs provide plausible explanations

CONDITIONAL/Unclassified

- Event or laboratory test abnormality

- More data for proper assessment needed, or

- Additional data under examination

UNASSESSABLE/UNCLASSIFIABLE: Report suggesting an adverse reaction

- Cannot be judged because information is insufficient or contradictory

- Data cannot be supplemented or verified
REFERENCES

E1. Brown SG. Clinical features and severity grading of anaphylaxis. J Allergy Clin Immunol 2004;114:371-6

E2. WHO Collaborating Centre for Drug Statistics Methodology. ATC/DDD index. 2019. Available from: https:/www.whocc,no/atc_ddd_index/. Accessed January 2, 2019. 